\title{
Primary Versus Accessory Respiratory Muscles Response to Kinesio Tape in Normal Subjects
}

\author{
AHMED A. ABD AL-RAHEEM, M.Sc.; HALA E. HAMED, Ph.D. and MARIAM E. MOHAMMED, Ph.D. \\ The Department of Physical Therapy for Cardiovascular/Respiratory Disorders \& Geriatrics, Faculty of Physical, \\ Cairo University
}

\begin{abstract}
Background: Kinesio Tape is claimed to have the effect of increasing muscular strength.

Aim of Study: Was to find the effect of the Kinesio tape as a muscle technique applied to the primary respiratory muscles and accessory respiratory muscles on Maximum Inspiratory Pressure (MIP) and Maximum Expiratory Pressure (MEP).
\end{abstract}

Material and Methods: Sixty normal individuals their ages ranged from 20 to 30 years old. They were recruited from under \& post graduate students at Faculty of Physical Therapy, Cairo University. The subjects were randomly divided into 2 groups equal in number, Group A included 30 subjects, the Kinesio tape was applied to the primary inspiratory muscles (diaphragm and scaleni) of the subjects. Group B included 30 subjects, the Kinesio tape was applied to the sternocleidomastoid (as accessory inspiratory muscle) and to the external abdominal oblique and internal abdominal oblique (as accessory expiratory muscles). The Kinesio tape application session was once every 4 days for a total study program of three weeks.

Results: There was a significant increase in the MIP in the group (A) compared with that of group (B) after the study program and there was a significant increase in the MEP in the group (B) compared with that of group (A) after the study program.

Conclusion: The results of this study support the importance of applying Kinesio tape over respiratory muscles to improve their functions.

Key Words: Kinesio tape-Respiratory muscles.

\section{Introduction}

KINESIO Tape (KT) is an elastic tape which was known for its therapeutic effects than as a taping

Correspondence to: Dr. Ahmed A. Abd Al-Raheem, The Department of Physical Therapy for Cardiovascular/ Respiratory Disorders \& Geriatrics, Faculty of Physical, Cairo University technique. It is a method of taping developed in japan in 1973 by a kinesiologist Kenzo Kase [1] to help with the functionality of the body and its natural healing process. The makers of the tape were experimenting with different types of tapes and taping techniques and developed the material. Step by step Kase gradually improved the different techniques based on his professional experience. It was later introduced into United States in the 1995 and the technique gained more popularity when it was used on athletes during the Beijing Olympics in 2008.

The structure of the tape and the application technique results in the therapeutic effects of $\mathrm{Ki}$ nesio tape. These effects include improving circulation of the blood and lymph, decreasing pain, stimulating proprioception, stabilizing articulars and restoring muscle tone [2]

The effect of Kinesio taping on muscular strength depends on the application technique. Taping from the insertion of muscle to its origin inhibits muscle function, whereas taping from the muscle origin to insertion facilitates the muscle function [3].

The diaphragm, which is a primary respiratory muscle, acts as a piston. It lowers pleural pressure and inflates the lungs by moving in the caudal direction with the ribs [4]. The scalene and sternocleidomastoid muscles increase respiratory capacity by moving the sternum and rib cage in the cranial direction. While the sternocleidomastoid muscle is active as an accessory muscle only during forced inspiration, scaleni muscles are always active as primary respiratory muscles [5]. The internal and external abdominal oblique muscles are forced expiratory muscles that help the exhalation of air 
by increasing the abdominal pressure during forced expiration [6].

Respiratory muscles have striated muscle structure embryologically, morphologically and functionally and show fatigue after overwork. Some researchers claimed that inhibitor signals are generated, reducing motor command when fatigue in the muscles continues and this leads to respiratory insufficiency [7].

Even though kinesiology taping is claimed to have the effect of increasing muscular strength, the results of the limited studies on this topic are contradictory.

Therefore, our aim was to investigate the effect of kinesiology taping on primary inspiratory, accessory inspiratory and expiratory muscles strength.

Respiratory pressure gauge with maximum effort indicator is the preferred and recommended one-way valve setup for measuring either inspiratory or expiratory pressure it consists of a T-piece with $22 \mathrm{~mm}$ ends to which one-way valves are attached. Depending on which valve is closed off (capped), it measures either inspiratory or expiratory pressure. An 18 inch $(45 \mathrm{~cm})$ long flexible tube is attached to the center of the "T" the other end is attached to the gauge.

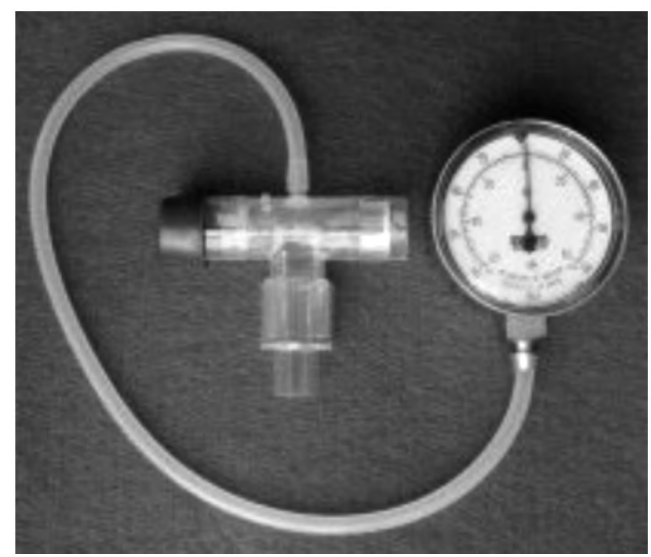

Fig. (1): Respiratory pressure Gauge with maximum effort indicator.

\section{Subjects and Methods}

This is a randomized controlled study that was carried on sixty normal male individuals, their ages ranged from 20 to 30 years old. The subjects were recruited from under \& post graduate students at Faculty of Physical Therapy, Cairo University. During the period between November 2017 and February 2018. The subjects were randomly divided into 2 groups equal in number, group (A) 30 subjects in which Kinesio tape was applied to the primary inspiratory muscles (diaphragm and scaleni) of the subjects. Group (B) 30 subjects in which Kinesio tape was applied to the sternocleidomastoid (as accessory inspiratory muscle) and to the external abdominal oblique and internal abdominal oblique (as accessory expiratory muscles).

The participated subjects were normal male individuals, their age ranged from 20 to 30 years old, they were within normal average of body mass index $\left(18: 25 \mathrm{~kg} / \mathrm{m}^{2}\right)$ and their waist circumference was $<94 \mathrm{~cm}$. The exclusion criteria were smoking, musculoskeletal deformities, acute or chronic chest diseases, neuromuscular diseases, surgical conditions, acute or chronic infections and cardiovascular disorders.

\section{Methods:}

Maximum inspiratory and expiratory muscles strength were evaluated with a respiratory pressure Gauge with maximum effort indicator through a mouthpiece.

\section{Application procedures:}

The application procedures were done for a period of three weeks.

Kinesio tape was applied every 4 days.

Group A: The Kinesio tape was applied to the primary inspiratory muscles (diaphragm and scaleni) of the subjects. Two tapings were applied to the diaphragm, from the abdomen and back. Starting position from the abdomen: The participant was standing with his trunk in hyperextension and both arms overhead. The base point of the tape was applied on the xiphoid process without tension and the tails of the tape were applied towards the ribs with no tension. Starting position from the back: The participant was standing. The projection of the xiphoid process on the back was determined as the base and the tails of the tape was applied towards the ribs without any tension. Scaleni taping: The participant was in the sitting position when the neck of the participant is in the lateral flexion and rotation to the opposite side to be taped. Taping was repeated on the opposite side.

Group B: The Kinesio tape was applied to the sternocleidomastoid (as accessory inspiratory muscle) and to the external abdominal oblique and internal abdominal oblique (as accessory expiratory muscles). Sternocleidomastoid taping: Participant 
was sitting and his neck was in lateral flexion to the opposite side and rotation to the same side to be taped and in rotation to the same side. Taping was repeated on the opposite side, external abdominal oblique muscle taping: Participant position: Supine with semi flexed hip and knee, the torso was rotated to the same side and legs were rotated to opposite side, taping was repeated on the opposite side, internal abdominal oblique muscle taping: Participant position: Supine with semi flexed hip and knee the torso was rotated to the opposite side and legs were rotated to same side. Taping was repeated on the opposite side.

Maximum inspiratory muscles strength was measured during forced inspiration following expiration and maximum expiratory muscles strength was measured during forced expiration following deep inspiration through the mouthpiece of the device while the subject in sitting position and had a nose clips. The measurements were repeated 3 times and the highest value was recorded.

\section{Statistical analysis:}

Descriptive statistics and $t$-test was conducted for comparison of the mean age, body mass index and waist circumference between both groups, $t$ test was conducted for comparison of pre and post the study program mean values of MIP and MEP between groups. Paired $t$-test was conducted for comparison between pre and post the study program mean values of MIP and MEP in each group. The level of significance for all statistical tests was set at $p<0.05$. All statistical measures were performed through the Statistical Package for Social Studies (SPSS) Version 19 for windows.

\section{Results}

There was a significant increase in the MIP in the group A compared with that of group B after the study program.

Table (1): $t$-test for comparison between after the study program mean values of MIP of group A and B.

\begin{tabular}{|c|c|c|c|c|c|}
\hline & $\begin{array}{l}\mathrm{MIP}\left(\mathrm{cmH}_{2} \mathrm{O}\right) \\
\quad \mathrm{X} \pm \mathrm{SD}\end{array}$ & MD & $\begin{array}{c}t- \\
\text { value }\end{array}$ & $\begin{array}{c}p- \\
\text { value }\end{array}$ & Sig. \\
\hline $\begin{array}{l}\text { Group A } \\
\text { Group B }\end{array}$ & $\begin{array}{l}96.53 \pm 5.56 \\
88.26 \pm 5.84\end{array}$ & 8.27 & 5.61 & 0.0001 & S \\
\hline $\begin{array}{ll}\mathrm{X} & : \mathrm{I} \\
\mathrm{MD} & : \mathrm{I} \\
p \text {-value } & : \mathrm{I}\end{array}$ & $\begin{array}{l}\text { Mean. } \\
\text { Mean Difference. } \\
\text { Probability value. }\end{array}$ & & $\begin{array}{ll}\mathrm{SD} & : \mathrm{S} \\
- \text {-value } & : \mathrm{P} \\
& : \mathrm{S}\end{array}$ & $\begin{array}{l}\text { tandard De } \\
\text { aired } t \text {-valu } \\
\text { ignificant. }\end{array}$ & ion. \\
\hline
\end{tabular}

There was a significant increase in the MEP in the group B compared with that of group A after the study program.
Table (2): $t$-test for comparison between after the study program mean values of MEP of group A and B.

\begin{tabular}{|c|c|c|c|c|c|}
\hline & $\begin{array}{c}\mathrm{MEP}\left(\mathrm{cmH}_{2} \mathrm{O}\right) \\
\mathrm{X} \pm \mathrm{SD}\end{array}$ & MD & $\begin{array}{c}t- \\
\text { value }\end{array}$ & $\begin{array}{c}p- \\
\text { value }\end{array}$ & Sig. \\
\hline $\begin{array}{l}\text { Group A } \\
\text { Group B }\end{array}$ & $\begin{array}{l}77.6 \pm 9.59 \\
84.9 \pm 6.71\end{array}$ & -7.3 & -3.41 & 0.001 & $\mathrm{~S}$ \\
\hline $\begin{array}{l}\mathrm{X} \\
\mathrm{MD} \\
p \text {-value }: \mathrm{I}\end{array}$ & $\begin{array}{l}\text { an. } \\
\text { an Difference. } \\
\text { bability value. }\end{array}$ & & $\begin{aligned} & : \mathrm{St} \\
& : \mathrm{Pa} \\
& : \mathrm{Si}\end{aligned}$ & $\begin{array}{l}\text { dard De } \\
\text { ed } t \text {-valu } \\
\text { ificant. }\end{array}$ & \\
\hline
\end{tabular}

\section{Discussion}

This study was conducted to investigate the effect of the Kinesio tape muscle technique applied to the primary respiratory muscles and accessory respiratory muscles on maximum inspiratory and expiratory muscles pressure on sixty normal male individuals, their ages ranged from 20 to 30 years old. They were divided into two equal groups that received Kinesio tape application every 4 days for a period of three weeks.

The values of maximum inspiratory muscles strength and maximum expiratory muscles strength were recorded before and after the study program.

Within the limitation of the study, it was showed a significant increase in the MIP in the group A compared with that of group B post the study program, and there was a significant increase in the MEP in the group B compared with that of group A post the study program. The results of this study support the importance of applying Kinesio tape over respiratory muscles to improve their functions.

A number of studies have evaluated the acute effect of kinesiology taping. Kenzo Kase [8] claimed that the effect of kinesiology taping lasts for 3-4 days.

Therefore, it is possible that an increase in muscle activation following kinesiology taping will emerge in long-term applications and the results of acute evaluation might be misleading. This view is consistent with the results of Slupik et al., [9] who reported an increase in vastus medialis muscle strength after taping that reached its peak level within 24 hours and lasted for a further 48 hours following removal of the tape.

In agreement with our study, Minsoo et al., [10] conducted a study on Healthy 20 males were divided into Inspiratory Muscle Training (IMT) group (control group) and IMT with tape group (experimental group). 
Kinesio tape was applied on the inspiratory agonist diaphragm and scalene, sternocleidomastoid and pectoralis minor. The inspiratory pulmonary muscle strength was measured by the maximal inspiratory pressure (PI max) and Minute Volume (MV) using the Respifit S and the pulmonary function were measured Peak Expiratory Flow (PEF), forced vital capacity (FVC), forced expiratory volume in $1 \mathrm{sec}\left(\mathrm{FEV}_{1}\right), \mathrm{FEV}_{1} / \mathrm{FVC}$ using the Spirometer and compared before and after. Showed that the PI max value for experimental group increased significantly than that of control group. Therefore Kinesio tape maximizes inspiratory muscle exercise effect on muscle strength improvement.

Williams et al., [11] meta-analysis found that 7 out of 10 investigated studies showed that KT had some substantial effects on muscle activity, for quadriceps and hamstrings peak torque, and grip strength measures, concluded that KT may have a small beneficial role in improving strength. Nevertheless, in three isokinetic studies, no significant effect on muscle strength was found when KT was applied to the quadriceps of healthy subjects [1214].

On the other hand, a study of healthy participants investigating KT application on the biceps brachii concentric elbow peak torque significantly increased even when compared to placebo taping $[15,16]$

Another meta-analysis of 19 studies, investigated the efficacy of Kinesio taping in facilitating contraction and increasing muscle strength in healthy adults, comprising data of 530 subjects and 48 pairwise comparisons of muscle strength were included. The methodological quality of these studies ranged from moderate to good. Concluded that the application of Kinesio tapes may have some therapeutic benefits, but the usage of KT to facilitate muscular contraction has no or only negligible effects on muscle strength and the strength-enhancing effects of KT are not musclegroup dependent [17].

Kase [8] stated that only little data exist in which KT has been shown to exert an immediate effect on muscle strength in an experimental setting. Indeed, although its creators claimed that the application of KT increased muscular strength. Lumbroso et al., [18] said that the majority of studies have evaluated only the immediate effect of Kinesio taping rather than later effects.

Huang et al., [19] found that KT applied to the gastrocnemius muscle immediately increased ver- tical ground reaction forces and EMG activity of the gastrocnemius while performing a vertical jump.

Also, Lumbroso et al., [18] found that KT application on the gastrocnemius caused a significant increase of its peak force immediately and after two days of wearing the KT. KT application over the hamstrings or gastrocnemius, did not cause an immediate change of hamstring peak force, however, after two days of wearing KT, hamstring peak force, significantly increased.

\section{Conclusion:}

The encouraging results of this study showed that the application of Kinesio tape over main and accessory respiratory muscles improve their functions.

\section{References}

1- MILLER C.M., GREENWOOD S., GLESSON M., NARDNE F. and FAIGLE K.: Kinesio taping and hypotonia, International organization of physical therapy in pediatrics, 115: 2-10, 2009.

2- HALSETH T., McCHESNEY J.W., DEBELISO M., VAUGHN R. and LIEN J.: The effect of kinesio taping on propioception at the ankle. J. Sport Sci. Med., 3: 1-7, 2004.

3- LIU Y.H., CHEN S.M., LIN C.Y., et al.: Motion Tracking on Elbow Tissue from Ultrasonic Image Sequence for Patients with Lateral Epiconylitis. 29th Annual International Conference of the IEEE EMBS Cite. Internationale, Lyon, France, August 23-6, 2007.

4- De TROYER A., LEDUC D., CAPPELLO M., et al.: Mechanisms of the inspiratory action of the diaphragm during isolated contraction. J. Appl. Physiol., 107: 173642, 2009.

5- CHITI L., BIONDI G., MORELOT-PANZINI C., et al.: Scalene muscle activity during progressive inspiratory loading under pressure support ventilation in normal humans. Respir. Physiol. Neurobiol., 164: 441-8, 2008.

6- OVECHKIN A., VITAZ T., De PALEVILLE D.T., et al.: Evaluation of respiratory muscle activation in individuals with chronic spinal cord injury. Respir. Physiol. Neurobiol. 173: 171-8, 2010.

7- KARATURAN YELMEN N., ȘAHIN G., GEMICIO ־GLU B., et al.: Kronik Obstrüktif Akci ger Hastalı gında Solunum Kaslarının Aktivitesinin İncelenmesi. Solunum, 5: 10-14, 2003.

8- KASE K., WALLIS J. and KASE T.: Clinic Therapeutic Applications of The Kinesio Taping Method. 2nd Edition. Japan: Kinesio Taping Association, p. 12, 2003.

9- SLUPIK A., DWORNIK M., BIALOSZEWSKI D. and ZYCH E.: Effect of kinesio taping on bioelectrical activity of vastus medialis muscle. Preliminary report. Orthop. Traumatol. Rehabil., 9: 644-51, 2007.

10- MINSOO L., MYUNGCHUL K. and CHUNGJOA A. Impact of Concurrent Inspiratory Muscle Training and 
Tape on Inspiratory Muscle Strength, Endurance and Pulmonary Function. Journal of The Korean Society of Integrative Medicine, 2 (3): 65-73, 2014.

11-WILLIAMS S., WHATMAN C., HUME P.A. and SHEERIN K.: Kinesio taping in treatment and prevention of sports injuries: A meta-analysis of the evidence for its effectiveness. Sports Med., 42: 153-64, 2012.

12- FU T.C.,WONG A.M.,PEI Y.C., WU K.P., CHOU S.W. and LIN Y.C.: Effect of kinesio taping on muscle strength in athletes-A pilot study. J. Sci. Med. Sport, 11: 198-201, 2008.

13- LINS C.A., NETO F.L., AMORIM A.B., MACEDO L.D. and BRASILEIRO J.S.: Kinesio Taping $((\mathrm{R}))$ does not alter neuromuscular performance of femoral quadriceps or lower limb function in healthy subjects: Randomized, blind, controlled, clinical trial. Manual therapy: [Epub ahead of print], 2012.

14- VERCELLI S., SARTORIO F., FOTI C., COLLETTO L., VIRTON D., RONCONI G. and FERRIERO G.: Immediate effects of kinesiotaping on quadriceps muscle strength: A singleblind, placebo-controlled crossover trial. Clinical journal of sport medicine: Official Journal of the Canadian Academy of Sport Medicine, 22 (4): 319-26, 2012.
15- FRATOCCHI G., Di MATTIA F., ROSSI R., MANGONE M., SANTILLI V. and PAOLONI M.: Influence of Kinesio Taping applied over biceps brachii on isokinetic elbow peak torque. A placebo controlled study in a population of young healthy subjects. J. Sci. Med. Sport, 16 (3): 245$9,2012 \mathrm{a}$.

16- FRATOCCHI G., Di MATTIA F., ROSSI R., MANGONE M., SANTILLI V. and PAOLONI M.: Influence of Kinesio Taping applied over biceps brachii on isokinetic elbow peak torque. A placebo controlled study in a population of young healthy subjects. Journal of Science and Medicine in Sport: [Epub ahead of print], 2012b.

17- ROBERT CSAPOA and LUIS M. ALEGRE: Effects of Kinesio taping on skeletal muscle strength-Ameta-analysis of current evidence. J. Sci. Med. Sport, Vol. 18 (4): 4506, 2015.

18- LUMBROSO D., ZIV E., VERED E. and KALICHMAN L.: The Effect of Kinesio Tape Application on Hamstring and Gastrocnemius Muscles in Healthy Young Adults. J. of Bodywork \& Movement Therapies, 18 (1): 130-8, 2013.

19- HUANG C.Y., HSIEH T.H., LU S.C. and SU F.C.: Effect of the Kinesio tape to muscle activity and vertical jump performance in healthy inactive people. Biomedical Engineering Online, 10: 70, 2011.

\section{إستجابة ضغط عضلات التنفس الآساسية والمساعدة

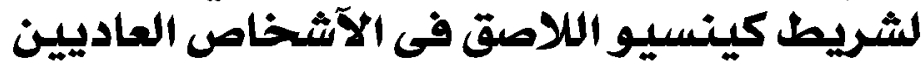

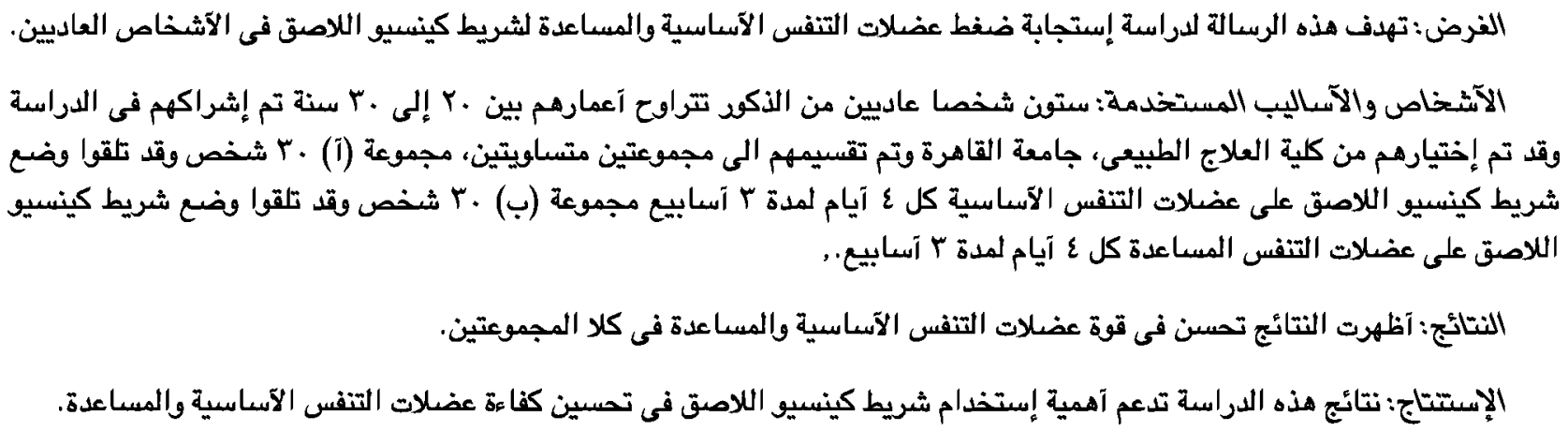

